Research report

\title{
Do burnout and work engagement predict depressive symptoms and life satisfaction? A three-wave seven-year prospective study
}

\author{
Jari J. Hakanen ${ }^{\text {a,* }}$, Wilmar B. Schaufeli ${ }^{\text {b }}$ \\ ${ }^{a}$ Finnish Institute of Occupational Health, Centre of Expertise for Work Organizations, Finland \\ b University of Utrecht, Department of Social and Organizational Psychology, The Netherlands
}

\section{A R T I C L E I N F O}

\section{Article history:}

Received 3 February 2012

Received in revised form 28 February 2012

Accepted 28 February 2012

Available online 24 March 2012

\section{Keywords:}

Burnout

Depression

Work engagement

Life satisfaction

Dentists

Prospective study

\begin{abstract}
A B S T R A C T
Background: Burnout and work engagement have been viewed as opposite, yet distinct states of employee well-being. We investigated whether work-related indicators of well-being (i.e. burnout and work engagement) spill-over and generalize to context-free well-being (i.e. depressive symptoms and life satisfaction). More specifically, we examined the causal direction: does burnout/work engagement lead to depressive symptoms/life satisfaction, or the other way around?

Methods: Three surveys were conducted. In 2003, 71\% of all Finnish dentists were surveyed $(n=3255)$, and the response rate of the 3 -year follow-up was $84 \%(n=2555)$. The second follow-up was conducted four years later with a response rate of $86 \%(n=1964)$. Structural equation modeling was used to investigate the cross-lagged associations between the study variables across time.

Results: Burnout predicted depressive symptoms and life dissatisfaction from T1 to T2 and from T2 to T3. Conversely, work engagement had a negative effect on depressive symptoms and a positive effect on life satisfaction, both from $\mathrm{T} 1$ to $\mathrm{T} 2$ and from $\mathrm{T} 2$ to $\mathrm{T} 3$, even after adjusting for the impact of burnout at every occasion.

Limitations: The study was conducted among one occupational group, which limits its generalizability.

Conclusions: Work-related well-being predicts general wellbeing in the long-term. For example, burnout predicts depressive symptoms and not vice versa. In addition, burnout and work engagement are not direct opposites. Instead, both have unique, incremental impacts on life satisfaction and depressive symptoms.
\end{abstract}

(c) 2012 Elsevier B.V. All rights reserved.

\section{Introduction}

Both negative (e.g. burnout) and positive (e.g. being engaged) states experienced at work are related to mental wellbeing and health (Ahola et al., 2005; Erdogan et al., 2011; Faragher et al., 2005; Hakanen et al., 2008a; Schaufeli et al., 2009a, 2009b). The term burnout was first introduced by psychologist Herbert Freudenberger (1974) who described it as a

\footnotetext{
* Corresponding author at: Finnish Institute of Occupational Health, Work Organizations, Topeliuksenkatu 41 a A, Fl-00250 Helsinki, Finland. Tel.: + 35830 474 2453; fax: + 35892413496.

E-mail address: jari.hakanen@ttl.fi (J.J. Hakanen).
}

negative, job related psychological state comprising a set of symptoms such as physical fatigue, emotional exhaustion, and loss of motivation. Soon after and independently of Freudenberg, Cristina Maslach (1976) defined burnout remarkably similarly as a multi-dimensional stress syndrome consisting of mental fatigue (emotional exhaustion) and negative perceptions and feelings about clients or patients (depersonalization), and somewhat later also a crises in professional competence (reduced personal accomplishment) was included as a third component of burnout (Maslach and Jackson, 1981). Burnout has costs for organizations, as well as for society at large because it is related to higher absenteeism (Ahola et al., 2008), chronic work disability (Ahola et al., 2009a, 2009b), hospital admissions due 
to mental and cardiovascular disorders (Toppinen-Tanner et al., 2009), turnover (Shimizu et al., 2005), and poorer job performance (Taris, 2006a).

The relationship between burnout and depression remains unclear. Already Freudenberg (Freudenberger and Richelson, 1980) argued that the symptoms of burnout are job-related and situation-specific, whereas depressive symptoms are typically generalized to all other situations and spheres of life. Similarly, Warr (1987) made a distinction between jobrelated burnout and context-free depression. On the other hand, due to conceptual overlap, it has also been questioned whether the two can be distinguished from each other (Taris, 2006b). Empirically, however, previous studies have consistently shown that burnout and depressive symptoms are distinct but inter-related negative moods (e.g. Ahola et al., 2005; Bakker et al., 2000; Glass and McKnight, 1996; Iacovides, et al., 1999; Leiter and Durup, 1994; Shirom and Ezrach, 2003). A crucial unsolved issue is the causal order between both mental states. It has been assumed that burnout is a phase in the development of depression (Ahola et al., 2006; Iacovides, et al., 2003), hence implying that it precedes depression. However, the few existing longitudinal studies are inconclusive. For instance, McKnight and Glass (1995) found that rather than impacting each other, burnout and depressive symptoms may co-develop "in tandem". A three-year prospective study by Ahola and Hakanen (2007), which included both earlier waves of the present sample, showed that of those dentists with burnout but without depressive symptoms at baseline, $23 \%$ reported depressive symptoms at follow-up. Similarly, of those with depressive symptoms at baseline but without burnout symptoms, 63\% had developed burnout symptoms three years later. These results seem to suggest that both negative states may foster each other. On the other hand, using the whole sample and a two-wave cross-lagged panel analysis, Hakanen et al. (2008a) found that burnout predicted depressive symptoms (and not the other way round) three years later. Finally, using a crosssectional retrospective design, Nyklíček and Pop (2005) showed that having experienced a depressive episode earlier in life or a history of depression in close family members independently predicted current burnout. To our knowledge, the present study is the first three-wave study with a long enough follow-period (seven years altogether) to reveal the causal order between burnout and depressive symptoms in the long run.

Thanks to the rise of positive psychology (Seligman and Csikszentmihalyi, 2000), work-related well-being is now better understood, not only as absence of strain like burnout but also as a truly positive state, e.g. as work engagement (Schaufeli and Bakker, 2010). There are two main approaches to conceptualize work engagement. First, it has been considered as a direct opposite of burnout (Maslach et al., 2001). According to this view, work engagement is characterized by energy, involvement, and efficacy, which is opposite to exhaustion, cynicism, and lack of efficacy, respectively - the three constituting elements of burnout (Maslach and Leiter, 1997). Since burnout and engagement are assumed to be ends of the same continuum it is posited that both opposite states can be assessed using the Maslach Burnout Inventory (MBI: Maslach and Jackson, 1981). High scores on the MBI would be indicative of burnout, whereas low scores would be indicative of work engagement. According to the alternative view, work engagement is considered independently from burnout and defined as "a positive, fulfilling state of mind that is characterized by vigor, dedication, and absorption" (Schaufeli et al., 2002). Thus, contrary to those who suffer from burnout, engaged employees have a sense of energetic and effective connection with their work activities (Schaufeli and Salanova, 2006). In this alternative view, work engagement and burnout are considered distinct albeit negatively related constructs, and this distinctiveness is indeed confirmed by a recent meta-analysis (Halbesleben, 2010). In addition, longitudinal studies have shown that, for example, work engagement may negatively predict frequency of sickness absences (Schaufeli et al., 2009a, 2009b), and positively influence organizational commitment (Hakanen et al., 2008a), and work-family enrichment (Hakanen et al., 2011b). A recent study also suggests that the vigor dimension of work engagement (operationalized as a direct opposite of exhaustion) may act as an antecedent that reduces future symptoms of depression and anxiety (Seppälä et al., 2012). Thus, work engagement may have positive organizational, individual as well as family-related consequences. This means that work engagement could protect from depression, because engagement is an active and energetic psychological state which fosters the mobilization of resources even in mentally challenging conditions.

Finally, similar to work-related well-being, which consists of both being work engaged (positive state) and lacking burnout symptoms (negative state), general well-being is more than the lack of depressive symptoms (negative state). In addition, general well-being is also constituted by the presence of a positive state; being satisfied with one's life. Life satisfaction refers to a cognitive and global evaluation of the quality of one's life as a whole (McDowell, 2010; Pavot and Diener, 1993). According to two recent reviews life satisfaction has been associated with reduced mortality in healthy population studies (Chida and Steptoe, 2008) and with many other positive outcomes, such as organizational commitment, job performance and turnover intentions (Erdogan et al., 2011). However, life satisfaction research has largely ignored the work domain and has mainly investigated nonwork populations, and when focused on work-life issues, it has remained atheoretical (Erdogan et al., 2011).

In the current study, we examined whether positive (work engagement) and negative (burnout) work-related states would predict both positive (life satisfaction) and negative (depressive symptoms) general well-being (see Table 1). The theoretical rationale for this spillover hypothesis can be found in the conservation of resources theory (COR; Hobfoll, 1998). According to COR theory, burnout results from longterm threats (e.g. too high job demands) to one's energetic resources and/or actual loss of these resources after heavily investing in work without appropriate gains in return

Table 1

Conceptual model of the work-specific and general well-being in the present study.

\begin{tabular}{lll}
\hline & $\begin{array}{l}\text { Work-related mental } \\
\text { well-being }\end{array}$ & $\begin{array}{l}\text { General mental } \\
\text { well-being }\end{array}$ \\
\hline $\begin{array}{l}\text { Positive state } \\
\text { Negative state }\end{array}$ & $\begin{array}{l}\text { Work engagement } \\
\text { Burnout }\end{array}$ & $\begin{array}{l}\text { Life satisfaction } \\
\text { Depressive symptoms }\end{array}$ \\
\hline
\end{tabular}


(Shirom, 2003). Moreover, COR theory maintains that initial resource loss is likely to lead to loss spirals, i.e. to future losses of other resources and to subsequent deteriorated well-being (Hobfoll and Shirom, 1993). Indeed, research shows that burnout is related to several resource losses, e.g. to decreased self-efficacy (Leiter, 1992), increased work-family conflicts (Allen et al. 2000), and poorer coping strategies (Sears et al., 2000). Hence, because burnout is associated with progressive loss of resources which undermines the individual's coping capabilities we expect that this negative work-related state will spill-over and generalize into negative, context-free states like depressive symptoms and life dissatisfaction.

On the other hand, COR theory also assumes the possibility of gain spirals, i.e., those who possess resources, are likely to gain more resources over time (Hobfoll, 2001; Salanova et al., 2010). Work engagement is often experienced in resourceful jobs (that include autonomy, support, feedback etc.) (Halbesleben 2010). Feeling positive and energized (engaged) may be considered a surplus resource resulting from having a resourceful and meaningful job. Being engaged at work may further increase personal resources such as self-efficacy and optimism (Xanthopoulou et al., 2009), work-family enrichment (Hakanen et al., 2011b), and workability (Airila et al., 2012), and may thereby also spill-over to context-free well-being by positively influencing life satisfaction and negatively influencing depressive symptoms.

Thus, based on previous studies and theoretical reasoning, we expect that work-related well-being (burnout and work engagement) spills over to other life domains and generalizes to depressive symptoms and life satisfaction, respectively. In other words, we expect that work-related well-being predicts context-free well-being in the long-term. Alternatively, because the literature on the causal relationships between work-specific and general well-being is still inconclusive and longitudinal research is sparse, we also examined possible reversed or reciprocal effects, i.e., whether depressive symptoms and life satisfaction as indicators of context-free wellbeing could influence work-specific well-being (burnout and work engagement) rather than the other way around.

\section{Methods}

\subsection{Participants}

This study was part of a longitudinal research project that focused on well-being and health in dentistry. At baseline, a questionnaire was sent to all dentist members of the Finnish Dental Association (FDA) $(n=4588)$. Altogether, 3255 (71\%) dentists responded to the questionnaire at baseline (T1), and 2555 of those identified three years later $(n=3035)$ took part in the follow-up (T2) (84\%). In the third wave, four years after the first follow-up, in addition to having responded to two earlier surveys, 1964 dentists still participated in the study, which is $86 \%$ of those Time 2 participants who could be identified and $60 \%$ of the baseline participants.

At baseline T1, the sample was representative of all Finnish dentists in terms of age and gender (Hakanen, 2004). The participants of the third wave still accounted for approximately $49 \%$ of the dental profession in Finland. A comparison of the demographics and the study variables of the respondents who participated in all three waves $(N=1964)$ with those who dropped out after $\mathrm{T} 1(N=702)$ revealed some selective dropout. Namely, women (76.6\% vs. $64.4 \% ; \chi^{2}(1)=32.79$, $\mathrm{p}<.001)$, and after taking into account the retirement during the follow-up, older participants (average age of participants was 43.92 vs. 42.31 years for the dropouts; $\mathrm{p}<.001$ ) were slightly over-represented. Concerning the study variables, respondents participating at each of the time points showed a somewhat greater dedication than the non-respondents $(\mathrm{F}(1)=7.93, \mathrm{p}<.01)$ and less depressive symptoms $(\mathrm{F}(1)=$ $6.12, \mathrm{p}<.05)$ at $\mathrm{T} 1$. Because the participants did not differ on the basis of the other study variables (i.e. vigor, absorption, exhaustion, depersonalization, and life satisfaction) it seems unlike that these differences biased our results.

\subsection{Measures}

\subsubsection{Work engagement}

Work engagement was assessed with three subscales of the Utrecht Work Engagement Scale (UWES; Schaufeli et al., 2002). Vigor was assessed with six items $\left(\alpha_{\mathrm{T} 1}=.73, \alpha_{\mathrm{T} 2}=.75\right.$, and $\left.\alpha_{\mathrm{T} 3}=.81\right)$, dedication with five items $\left(\alpha_{\mathrm{T} 1}=.87, \alpha_{\mathrm{T} 2}=.86\right.$, and $\left.\alpha_{\mathrm{T} 3}=.84\right)$, and absorption with six items $\left(\alpha_{\mathrm{T} 1}=.81\right.$, $\alpha_{\mathrm{T} 2}=.83$, and $\alpha_{\mathrm{T} 3}=.81$ ). Items of work engagement were rated on a seven-point scale ranging from 0 ("never") to 6 ("always").

\subsubsection{Burnout}

Burnout was measured with two scales from the Maslach Burnout Inventory (MBI; Maslach and Jackson, 1981): emotional exhaustion ( 9 items; $\alpha_{\mathrm{T} 1}=90$, and $\alpha_{\mathrm{T} 2}=\alpha_{\mathrm{T} 3}=.91$ ) and depersonalization ( 5 items; $\alpha_{\mathrm{T} 1}=.73, \alpha_{\mathrm{T} 2}=.77$, and $\left.\alpha_{\mathrm{T} 3}=.78\right)$. The items were scored on a 7-point frequency rating scale ranging from 0 ("never") to 6 ("daily"). Originally the MBI includes also a third dimension, namely personal accomplishment which refers to the tendency to evaluate oneself negatively, particularly with regard to work with clients. However, evidence has accumulated that compared to emotional exhaustion and depersonalization reduced personal accomplishment plays a divergent role (Lee and Ashforth, 1996) and therefore exhaustion and depersonalization are considered the core dimensions of burnout (Schaufeli and Taris, 2005).

\subsubsection{Life satisfaction}

Life satisfaction was measured with the widely used Satisfaction with Life Scale (Pavot and Diener, 1993). The scale includes 5 items that are assessed on a 7-point scale ( $1=$ "strongly disagree", $7=$ "strongly agree"). Cronbach alphas were $\alpha_{\mathrm{T} 1}=.90$, $\alpha_{\mathrm{T} 2}=.90 \alpha_{\mathrm{T} 3}=.91$.

\subsubsection{Depressive symptoms}

Depressive symptoms were measured with the short form of the Beck Depression Inventory (BDI; Beck and Beck, 1972) which consists of 13 items with four alternatives for intensity; higher scores indicate more severe depressive symptoms. After examining the factorial structure of the measure we used two scales to indicate depressive symptoms (see also Byrne et al., 1996): negative emotions and attitudes (seven items covering such topics as sadness; $\alpha_{\mathrm{T} 1}=.78, \alpha_{\mathrm{T} 2}=\alpha_{\mathrm{T} 3}=.81$ ) and performance difficulties and somatic complaints (six items like social withdrawal; $\alpha_{\mathrm{T} 1}=.71, \alpha_{\mathrm{T} 2}=.72$, and $\alpha_{\mathrm{T} 3}=.71$ ). 


\subsection{Statistical analyses}

In order to investigate the cross-lagged longitudinal relationships between the study variables, we employed structural equation modeling (SEM) techniques using the AMOS 18.0 software package. Multiple indicators for each latent variable were used in the tested models. Work engagement was indicated by its three dimensions: vigor, dedication, and absorption. Burnout was indicated by its two core dimensions: exhaustion and depersonalization. Depressive symptoms were indicated by: (1) negative emotions and attitudes; and (2) performance difficulties and somatic complaints. Finally, unidimensional life satisfaction was indicated using five items. Several complementary fit indices were used to examine the overall quality and fit of the hypothesized and alternative models to the data: Comparative Fit Index (CFI), Normed Fit Index (NFI), Tucker Lewis Index (TLI), and Root Mean Square Error of Approximation (RMSEA). For CFI, NFI, and TLI, values greater than .90 (and preferably greater than .95 ) indicate a good fit between the model and the data (Hoyle and Panter, 1995; Hu and Bentler, 1999). An RMSEA value of .05 or less indicates a close fit, and values up to .08 would still indicate a reasonable error of approximation (Browne and Cudeck, 1993). The fit of nested models was compared by examining the significant changes in the Chi-square values and corresponding degrees of freedom. As regards non-nested models, we compared the chi-square/degrees of freedom ratio to evaluate the best fitting model: the smaller that value, the better the fit of the model (Wheaton et al., 1977).

As a preliminary step in the analyses, we tested the measurement model that defines the relations between all observed and unobserved study variables. The Confirmative Factor Analytic (CFA) measurement model specifies the pattern by which each measure loads on a particular factor (Byrne, 2001, p. 12) and presented a good fit to the data $\left(\chi^{2}=3018.04 ; \mathrm{df}=512\right.$; $\mathrm{CFI}=.95 ; \mathrm{TLI}=.94 ; \mathrm{NFI}=.95$; $\mathrm{RMSEA}=.050)$. In addition, we investigated the time invariance of the factor loadings at T1, $\mathrm{T} 2$, and $\mathrm{T} 3$. We found that the average difference in the factor loadings was only 0.026 and that the biggest difference in standardized factor loadings was between depersonalization measured at T1 and T3 (0.084). Therefore, we consider the factor loadings as invariant across the 7-year period. Taken together, our preliminary analyses confirm that the study variables can be distinguished from each other and that the contribution of the observed variables to the latent variables is rather stable across time.

Next, we tested the hypothesized spill-over model $\left(\mathrm{M}_{\text {work }}\right)$ in which both work engagement and burnout at $\mathrm{T} 1$ and $\mathrm{T} 2$ predict both life satisfaction and depressive symptoms at $\mathrm{T} 2$ and $\mathrm{T} 3$, respectively. We compared the hypothesized model with three alternatively plausible models using full panel designs, namely; (1) the stability model $\left(\mathrm{M}_{\text {stabil }}\right)$, which included the autoregressive effects over time of each latent variable but with all cross-lagged associations constrained to zero; (2) from general well-being to work-related well-being model $\left(\mathrm{M}_{\text {general }}\right)$, which included the autoregressive effects as in $\mathrm{M}_{\text {stabil }}$ combined with the reversed effects compared to $\mathrm{M}_{\text {work }}$, i.e., paths from life satisfaction and depressive symptoms from T1 and T2 to work engagement and burnout at T2 and T3 were added to the model; and (3) the reciprocal model $\left(\mathrm{M}_{\text {recipr }}\right)$ which was a combination of $\mathrm{M}_{\text {work }}$ and $\mathrm{M}_{\text {general. }}$.
Comparing these four models enabled us to test our spill-over hypothesis and also the direction of causality, for example, whether burnout predicts depressive symptoms or the other way around, or whether both mental states mutually influence each other.

All tested models included auto-regression effects in order to control for baseline levels, as suggested by Gollob and Reichardt (1991, p. 243-259). In addition, synchronous correlations between the latent variables were allowed in all tested models. Finally, the error terms of each indicator at T1, T2, and T3 were allowed to covary with each other, as is the recommended procedure in longitudinal structural equation models (Anderson and Williams, 1992).

\section{Results}

\subsection{Sample descriptives}

Table 2 shows that the dentists were mostly women (76\%) who had a permanent work contract (94\%). In addition, the majority worked full-time (83\%) and in the public sector (64\%).

\subsection{Bivariate relationships between the study variables}

Means, standard deviations, and Pearson correlations of all study variables are presented in Table 3.

\subsection{Longitudinal relationships}

Table 4 shows the fit indices of all tested models. The hypothesized spill-over model $\mathrm{M}_{\text {work }}$ fitted the data well. Moreover, model comparison with the Chi-square difference test showed that $\mathrm{M}_{\text {work }}$ had a significantly better fit to the data than the alternative stability model $\mathrm{M}_{\text {stabil }}\left(\Delta \chi^{2}=99.37\right.$, $\Delta \mathrm{df}=8, \mathrm{p}<.001)$. In addition, the fit indices showed that the

Table 2

Baseline characteristics of the study population ( $n=1964)$.

\begin{tabular}{|c|c|c|c|}
\hline Characteristic & $n(\%)$ & Characteristic & $n(\%)$ \\
\hline Sex & & Job tenure & \\
\hline Women & $1485(76)$ & $0-4$ years & $113(6)$ \\
\hline \multirow[t]{5}{*}{ Men } & $479(24)$ & 5-9 years & $240(12)$ \\
\hline & & $10-19$ years & $689(35)$ \\
\hline & & 20-29 years & $729(37)$ \\
\hline & & 30 years or more & $185(10)$ \\
\hline & & Missing data & $8(0)$ \\
\hline Age & & Supervisory position & \\
\hline 26-35 years & $294(15)$ & Yes & $518(26)$ \\
\hline $36-45$ years & 769 (39) & No & $1390(71)$ \\
\hline $46-55$ years & 759 (39) & Missing data & $56(3)$ \\
\hline 56-72 years & $142(7)$ & & \\
\hline Marital status & & Working hours & \\
\hline Unmarried & $147(7)$ & Full-time & $1626(83)$ \\
\hline Married or & $1651(84)$ & Shortened & $104(5)$ \\
\hline cohabiting & & Part-time & $220(11)$ \\
\hline Divorced or widowed & $159(8)$ & Missing data & $14(1)$ \\
\hline Missing data & $7(1)$ & & \\
\hline Professional sector & & Employment & \\
\hline Public & $1254(64)$ & Permanent & $1849(94)$ \\
\hline Private & $697(35)$ & Fixed-term & $103(5)$ \\
\hline Missing data & $13(1)$ & Missing data & $12(1)$ \\
\hline
\end{tabular}


Table 3

Means, standard deviations, and correlations between the study variables $(N=1964)$.

\begin{tabular}{|c|c|c|c|c|c|c|c|c|c|c|c|c|c|c|c|c|c|c|c|c|c|c|c|c|c|c|}
\hline Variables & M & $\mathrm{Sd}$ & 1. & 2. & 3. & 4. & 5. & 6. & 7. & 8. & 9. & 10. & 11. & 12. & 13. & 14. & 15. & 16. & 17. & 18. & 19. & 20. & 21. & 22. & 23. & 24. \\
\hline \multicolumn{27}{|l|}{ T1 (2003) } \\
\hline 1. Vigor $_{\mathrm{T} 1}$ & 4.54 & .99 & - & & & & & & & & & & & & & & & & & & & & & & & \\
\hline 2. Dedication ${ }_{\mathrm{T} 1}$ & 5.01 & 1.02 & .72 & - & & & & & & & & & & & & & & & & & & & & & & \\
\hline 3. Absorption & 3.78 & 1.36 & .51 & .50 & - & & & & & & & & & & & & & & & & & & & & & \\
\hline 4. Exhaustion ${ }_{\mathrm{T} 1}$ & 2.09 & 1.23 & -.32 & -.37 & .01 & - & & & & & & & & & & & & & & & & & & & & \\
\hline 5. Depersonalization $\mathrm{T}_{\mathrm{T} 1}$ & 1.19 & 1.04 & -.22 & -.28 & -.01 & .47 & - & & & & & & & & & & & & & & & & & & & \\
\hline 6. Life satisfaction $\mathrm{T}_{\mathrm{T} 1}$ & 5.30 & 1.20 & .34 & .40 & .18 & -.45 & -.26 & - & & & & & & & & & & & & & & & & & & \\
\hline 7. Depression: negative attitudes ${ }_{\mathrm{T} 1}$ & 1.14 & .26 & -.35 & -.39 & -.10 & .46 & .28 & -.56 & - & & & & & & & & & & & & & & & & & \\
\hline $\begin{array}{l}\text { 8. Depression: performance } \\
\text { difficulties }_{\mathrm{T} 1}\end{array}$ & 1.35 & .36 & -.39 & -.40 & -.09 & .61 & .36 & -.51 & .62 & - & & & & & & & & & & & & & & & & \\
\hline \multicolumn{27}{|l|}{ T2 (2006) } \\
\hline 9. Vigor $_{\mathrm{T} 2}$ & 4.60 & .91 & .67 & .55 & .39 & -.27 & -.21 & .31 & -.29 & -.31 & - & & & & & & & & & & & & & & & \\
\hline 10. Dedication $\mathrm{T}_{\mathrm{T}}$ & 4.99 & .96 & .56 & .70 & .38 & -.29 & -.25 & .35 & -.31 & -.32 & .73 & - & & & & & & & & & & & & & & \\
\hline 11. Absorption ${ }_{\mathrm{T} 2}$ & 3.79 & 1.34 & .39 & .37 & .66 & .02 & -.05 & .14 & -.08 & -.09 & .51 & .48 & - & & & & & & & & & & & & & \\
\hline 12. Exhaustion ${ }_{\mathrm{T} 2}$ & 2.22 & 1.28 & -.25 & -.30 & -.01 & .69 & .36 & -.37 & .36 & .47 & -.37 & -.39 & -.03 & - & & & & & & & & & & & & \\
\hline 13. Depersonalization ${ }_{\mathrm{T} 2}$ & 1.36 & 1.14 & -.19 & -.23 & -.02 & .37 & .64 & -.20 & .21 & .27 & -.27 & -.32 & -.06 & .53 & - & & & & & & & & & & & \\
\hline 14. Life satisfaction ${ }_{\mathrm{T} 2}$ & 5.25 & 1.18 & .29 & .34 & .15 & -.37 & -.23 & .66 & -.45 & -.41 & .40 & .44 & .16 & -.46 & -.29 & - & & & & & & & & & & \\
\hline $\begin{array}{l}\text { 15. Depression: negative } \\
\text { attitudes }_{\mathrm{T} 2}\end{array}$ & 1.16 & .28 & -.28 & -.33 & -.11 & .38 & .24 & -.42 & .63 & .45 & -.35 & -.40 & -.11 & .48 & .28 & -.60 & - & & & & & & & & & \\
\hline $\begin{array}{l}\text { 16. Depression: performance } \\
\text { difficulties }_{\mathrm{T} 2}\end{array}$ & 1.38 & .38 & -.28 & -.33 & -.07 & .49 & .29 & -.41 & .45 & .63 & -.41 & -.43 & -.12 & .64 & .36 & -.56 & .63 & - & & & & & & & & \\
\hline \multicolumn{27}{|l|}{ T3 (2010) } \\
\hline 17. Vigor $_{\mathrm{T} 3}$ & 4.59 & .97 & .61 & .52 & .38 & -.24 & -.20 & .26 & -.25 & -.29 & .67 & .56 & .39 & -.28 & -.23 & .29 & -.26 & -.30 & - & & & & & & & \\
\hline 18. Dedication ${ }_{\mathrm{T} 3}$ & 4.98 & .95 & .48 & .62 & .37 & -.24 & -.21 & .28 & -.25 & -.26 & .54 & .69 & .39 & -.26 & -.23 & .32 & -29 & -.30 & .75 & - & & & & & & \\
\hline 19. Absorption ${ }_{\mathrm{T} 3}$ & 3.80 & 1.37 & .38 & .37 & .65 & .00 & -.07 & .09 & -.05 & -.06 & .41 & .39 & .70 & -.03 & -.07 & .11 & -08 & -.07 & .54 & .53 & - & & & & & \\
\hline 20. Exhaustion ${ }_{\mathrm{T} 3}$ & 2.09 & 1.29 & -.18 & -.24 & -.01 & .62 & .33 & -.32 & .36 & .41 & -.24 & -.28 & -.02 & .68 & .40 & -.37 & .39 & .47 & -.34 & -.33 & -.04 & - & & & & \\
\hline 21. Depersonalization ${ }_{\mathrm{T} 3}$ & 1.28 & 1.12 & -.16 & -.21 & -.03 & .37 & .61 & -.18 & .22 & .25 & -.22 & -.25 & -.08 & .41 & .68 & -.30 & .25 & .31 & -.28 & -.30 & -.11 & .56 & - & & & \\
\hline 22. Life satisfaction ${ }_{\mathrm{T} 3}$ & 5.40 & 1.15 & .28 & .33 & .15 & -.37 & -.21 & .61 & -.44 & -.37 & .32 & .37 & .13 & -.39 & -.23 & .67 & -.48 & -.44 & .35 & .37 & .15 & -.46 & -.30 & - & & \\
\hline $\begin{array}{l}\text { 23. Depression: negative } \\
\text { attitudes }\end{array}$ & 1.16 & .28 & -.24 & -.29 & -.08 & .35 & .23 & -.37 & .56 & .38 & -.25 & -.32 & -.07 & .38 & .24 & -.42 & .64 & .45 & -.33 & -.35 & -.12 & .49 & .33 & -.59 & - & \\
\hline $\begin{array}{l}\text { 24. Depression: performance } \\
\text { difficulties }_{\mathrm{T} 3}\end{array}$ & 1.39 & .37 & -.25 & -.29 & -.08 & .43 & .25 & -.36 & .41 & 53 & -.30 & -.33 & -.11 & .48 & .29 & -.40 & .47 & .61 & -.40 & -.38 & -.12 & .62 & .40 & -.55 & .62 & - \\
\hline
\end{tabular}

Correlations $\geq .08$ are statistically significant, $\mathrm{p}<.001$; correlations between .06 and .07 are statistically significant, $\mathrm{p}<.01$; correlation .05 is statistically significant, $\mathrm{p}<.05$. 
Table 4

Fit statistics for the alternative study models $(N=1964)$.

\begin{tabular}{|c|c|c|c|c|c|c|c|c|c|c|c|}
\hline Model & Model description & $\chi^{2}$ & df & $\mathrm{CFI}$ & NFI & TLI & RMSEA & AIC & Model comparisons & $\Delta \chi^{2}$ & $\Delta \mathrm{df}$ \\
\hline MM & Measurement model & 3018.04 & 512 & .95 & .95 & .94 & .050 & 3398.04 & & & \\
\hline $\mathrm{M}_{\text {stabil }}$ & Stability model & 2444.21 & 543 & .96 & .96 & .96 & .042 & 2762.21 & & & \\
\hline $\mathrm{M}_{\text {work }}$ & $\begin{array}{l}\text { From work-related well-being to general } \\
\text { well-being model }\end{array}$ & 2344.85 & 535 & .97 & .96 & .96 & .042 & 2678.85 & $M_{\text {stabil VS. }} \mathrm{M}_{\text {work }}$ & $99.36^{* * *}$ & 8 \\
\hline $\mathrm{M}_{\text {general }}$ & $\begin{array}{l}\text { From general well-being to work-related } \\
\text { well-being model }\end{array}$ & 2416.69 & 535 & .97 & .96 & .96 & .042 & 2750.69 & $M_{\text {stabil }}$ VS. $M_{\text {general }}$ & $27.52^{* *}$ & 8 \\
\hline $\mathrm{M}_{\text {recipr }}$ & Reciprocal model & 2327.48 & 527 & .97 & .96 & .96 & .042 & 2677.48 & $\begin{array}{l}M_{\text {work }} \text { Vs. } M_{\text {recipr }} \\
M_{\text {stabil Vs. }} M_{\text {recipr }} \\
M_{\text {general }} \text { Vs. } M_{\text {recipr }}\end{array}$ & $\begin{array}{r}17.36^{*} \\
89.81^{* * *} \\
116.73^{* * *}\end{array}$ & $\begin{array}{r}8 \\
8 \\
16\end{array}$ \\
\hline
\end{tabular}

Note.

*** $\mathrm{p}<.001$

$* * \quad \mathrm{p}<.01$.

$* \mathrm{p}<.05$.

fit of $\mathrm{M}_{\text {work }}$ was superior to that of $\mathrm{M}_{\text {general }}$ which included cross-lagged paths from general well-being (depressive symptoms and life satisfaction) to work-related well-being (burnout and work engagement). Finally, according to the Chi-square difference test, the reciprocal model $\mathrm{M}_{\text {recipr }}$ had a slightly better fit than $\mathrm{M}_{\text {work }}\left(\Delta \chi^{2}=17.36, \Delta \mathrm{df}=8, \mathrm{p}<.05\right)$, although the other fit indices were practically the same and the $\chi^{2} / \mathrm{df}$ ratio was lower for $\mathrm{M}_{\text {work }}$ (4.38) than for $\mathrm{M}_{\text {recipr }}$ (4.42), which suggests that $\mathrm{M}_{\text {work }}$ would be a better fitting model. Indeed, both models had similar hypothesized cross-lagged effects and none of the reversed effects was significant in the reciprocal model. For these reasons, we report the results of the more parsimonious model $\mathrm{M}_{\text {work }}$ in Fig. 1.

According to $\mathrm{M}_{\text {work }}$ burnout at T1 predicted life dissatisfaction at T2 (st. $\beta$ was $-.09, \mathrm{p}<.001$ ) and similarly burnout at T2 predicted life dissatisfaction at T3 (st. $\beta$ was $-.11, \mathrm{p}<.001$ ). In addition, burnout at $\mathrm{T} 1$ impacted depressive symptoms at $\mathrm{T} 2$ (st. $\beta$ was .16, $\mathrm{p}<.001$ ) and burnout at T2 influenced depressive symptoms at T3 (st. $\beta$ was .15, $\mathrm{p}<.001$ ). Please note that independently from the impacts of earlier life satisfaction, depressive symptoms and burnout, work engagement had significant cross-lagged effects on both life satisfaction and depressive symptoms. More specifically, work engagement predicted life satisfaction from T1 to T2 (st. $\beta$ was .09, $\mathrm{p}<.001$ ) and from T2 to T3 (st. $\beta$ was .07, $\mathrm{p}<.01$ ). In addition, work engagement had cross-lagged effects on depressive symptoms from T1 to T2 and from T2 to T3 (at both times, st. $\beta$ was $-.06, \mathrm{p}<.01$ ). The best fitting model $\mathrm{M}_{\text {work }}$ explained 57\% (T2) and 59\% (T3) of the variance of burnout, and 61\% (T2) and 59\% (T3) of the variance of work engagement. In addition, $54 \%$ of the variance of depressive symptoms and $48 \%$ of the variance of life satisfaction both at T2 and T3 were explained by the model.

All in all, our hypothesis on the spill-over of work-related positive and negative states on general well-being were fully supported, meaning that both burnout and work engagement predicted, albeit in opposite directions, life satisfaction and depressive symptoms both from T1 to T2 and from T2 to T3.

\section{Discussion}

We used a three-wave seven-year follow-up design and a national sample of Finnish dentists to investigate cross-lagged associations between burnout and work engagement (workrelated mental well-being) on the one hand, and depressive

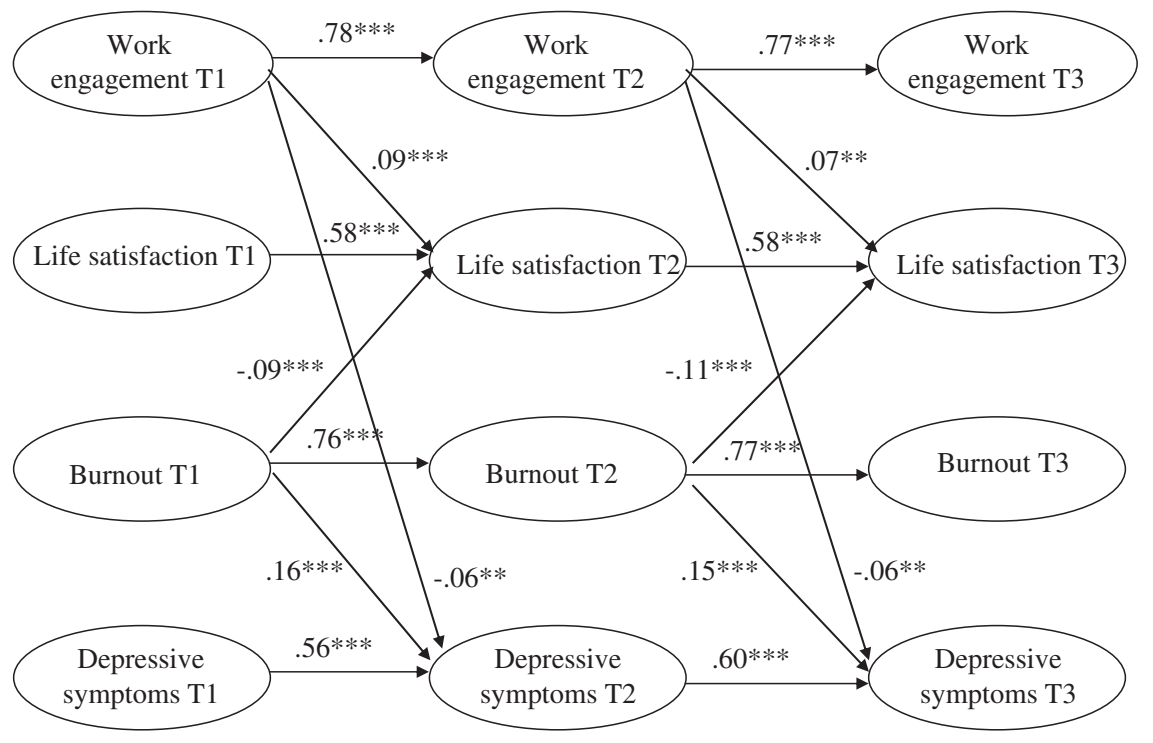

Fig. 1. The results of the final model $(N=1964)$. 
symptoms and life satisfaction (general well-being) on the other hand. The results supported our hypothesis that workrelated well-being spills-over to general, context free wellbeing, i.e. burnout and work engagement predict depressive symptoms and life satisfaction over time.

The current study contributes in four ways to the existing literature. First, it showed that burnout predicted depressive symptoms over periods of 3- and 4-years and not the other way round. Previous studies have shown that burnout and depressive symptoms are different nosological entities (Iacovides et al., 2003) and can be differentiated psychometrically, but yet share considerable variance (Schaufeli and Enzmann, 1998). So far longitudinal studies have found mixed results: burnout would precede depressive symptoms (Hakanen et al., 2008a); one's own or close family member's earlier depressive episodes would increase one's vulnerability to later burnout (Nyklíček and Pop, 2005); burnout could predict new cases with depressive symptomatology and also vice versa (Ahola and Hakanen, 2007); burnout and depressive symptoms would co-develop without influencing each other (McKnight and Glass, 1995). The present study is unique in that it included a prospective, three-wave design spanning seven years, so far the longest follow-up period. Therefore, the present findings lend considerable support for the assumption that burnout might be a phase in the development of depression (Ahola et al., 2006; Iacovides, et al., 2003).

Second, we found that the positive state of work engagement negatively predicted depressive symptoms over the seven-year study period. To our knowledge, the present study is the third longitudinal study showing that work engagement may have positive consequences for health and well-being. Previously Schaufeli et al. (2009a, 2009b) found that work engagement negatively predicted frequency of sickness absences (but was unrelated to the duration of sickness absences), and recently Innstrand et al. (2012) found that the vigor dimension of work engagement predicted low levels of depressive symptoms. In support of the present findings, previous cross-sectional studies have shown, for example, that work engagement is positively related to healthy, adaptive cardiac autonomic activity, particularly increased parasympathetic activity (Seppälä et al., 2012), to low levels of distress (Schaufeli et al., 2008), and to workability (Airila et al., 2012). A simple explanation for the negative association between engagement and depressive symptoms is that engaged employees are rarely burned out, as shown by the negative correlations between the dimensions of work engagement and burnout, and therefore they are not depression prone. In addition, being engaged, i.e., feeling vigorous and enthusiastic at work, is related to proactive behavior (Hakanen et al., 2008b; Salanova and Schaufeli, 2008) and to self-efficacy beliefs (Salanova et al., 2011), which may protect from depressive symptoms. Moreover, Hakanen et al. (2011b) showed that work engagement reciprocally and positively predicted positive work-family enrichment, which suggests that positive emotions and attitudes related to work engagement also spill over to private life and may thereby contribute to general well-being. In short, it seems that engaged employees can draw upon many resources that make it likely that they are caught in a gain spiral, which also produces context-free, general well-being.

Third, the current study showed that both burnout and work engagement had long-term effects on both depressive symptoms and life satisfaction, even after controlling for each other's effects on the alternative outcome variables. This finding attests that burnout and work engagement are not direct opposites as suggested by Maslach and Leiter (1997) and that they both contribute independently to the prediction of general well-being. In other words, burnout and work engagement have incremental validity vis-à-vis each other, the effect of one measure cannot be reduced to that of the other one, and vice versa. Thus, in order to protect employees from depressive symptoms and increase life satisfaction, the best option would be to focus on both factors and thus simultaneously prevent burnout and build work engagement.

Fourth, similarly to the discussion of the causal order of burnout and depressive symptomatology, it is unclear whether life satisfaction, being an indicator of context-free subjective well-being, influences domain-specific (e.g. work related) well-being, or the other way round (e.g. Pavot and Diener, 2008). In our study, both indicators of work-related well-being predicted generalized context-free well-being (depressive symptoms and life satisfaction). We did not find any reversed effects indicating that general well-being influences workrelated well-being. This finding suggests that experiences at work are particularly important for the individual's overall level of well-being and mental health in the long-term. In contrast, for work-related well-being other issues in life (e.g. life events, marital relationships) that influence general well-being (e.g. Pavot and Diener, 2008; Ryan and Deci, 2001) may not be so important as those that are work-related.

\subsection{Limitations}

At least five limitations should be discussed. First, our study was based on self-reports which runs the risk of common method variance. However, the longitudinal full panel design which controls for baseline levels of the study variables diminishes the risk for problems related to common method variance (Doty and Glick, 1998). In addition, Ahola et al. (2006) found a positive relationship between burnout and depression regardless of the depression measure, although the associations were stronger with self-report measures than with the use of a structured psychiatric interview. Nevertheless, it would be important for future research to replicate the present study by also including information on well-being from other sources, such as interviews, psycho-physiological parameters, or medical records.

Second, we focused on one professional group only; dentists. However, we assume that there are no reasons to expect that when using a similar design the effects found in the present study would not replicate in other samples as well. In addition, at baseline $71 \%$ of the whole profession of dentists participated in the study and the response rates in the follow-ups have been high ( $84 \%$ and $86 \%$, respectively). Consequently, there were only minor differences between the respondents and the non-respondents in the follow-ups so that selection bias is unlikely to play a role.

Third, although we investigated cross-lagged effects with a three-wave prospective design, strictly and philosophically speaking our study did not demonstrate causality between the study variables, i.e., relationships between an event (the cause) and a second event (the effect), where the second event is understood as a consequence of the first. However, 
we assessed all study variables three times which is considered a prerequisite for a truly longitudinal study (Ployhart and Vandenberg, 2010).

Fourth, we measured burnout by focusing on its two core symptoms, i.e., emotional exhaustion and depersonalization (Schaufeli and Taris, 2005), and excluded personal accomplishment which is included in the Maslach Burnout Inventory (MBI). It is noteworthy that Maslach and her colleagues originally had a working definition of burnout that only included its two core symptoms, and that on second thoughts and after a factor analysis personal accomplishment was added to the MBI (Maslach, 1993, p. 26). Since that time several studies have questioned the validity of this third burnout dimension, for example on the basis that rather than a burnout component it could reflect a personal characteristic (Cordes and Dougherty, 1993) or be a sequel of burnout (Shirom, 2003). Importantly, studies on the clinical validity of Maslach Burnout Inventory have shown that those who have received professional psychotherapeutic treatment and who have been diagnosed as "burned-out", report high levels of exhaustion and depersonalization (cynicism) but not reduced personal accomplishment (Roelofs et al., 2005; Schaufeli et al., 2001). Empirically, personal accomplishment (or professional efficacy as defined in the general version of MBI; MBI-GS) is relatively modestly related with both other burnout dimensions (Lee and Ashforth, 1996) and actually loaded on a work engagement factor (Schaufeli et al. 2002). Finally, in their multi-sample study Schaufeli and Salanova (2007) included a scale consisting of negatively worded items on professional inefficacy and showed that, whereas professional efficacy included in the MBI-GS loaded on the engagement factor, genuinely measured professional inefficacy loaded on the burnout factor. Thus, to measure personal accomplishment (or professional efficacy) as a dimension of burnout, it is not right to reverse the scale as is the practice in studies using MBI, but perhaps a measure of genuine inefficacy should be used. Because of the questionable role of personal accomplishment in burnout we focused on emotional exhaustion and depersonalization.

It can be considered a final limitation that we only examined relations between four types of psychological states over time. For example, we did not include variables related to working conditions that may influence burnout and work engagement and similarly, many other factors, such as marital relationships, life events, and economic subsistence may have effects on depressive symptoms and life satisfaction. However, many previous studies have focused on various life and working conditions as antecedents of the same indicators of well-being that were studied in the present study (e.g. Adams et al., 1996; Hakanen et al., 2011a; Schaufeli et al., 2009; Ylipaavalniemi et al., 2005), but there has been a lack of knowledge concerning longitudinal relationships between these indicators: burnout, work engagement, life satisfaction, and depressive symptoms.

\section{Conclusions}

Work-related states of mind such as burnout and work engagement, predict both depressive symptoms and life satisfaction in the long-term, rather than the other way around. The positive effects of work engagement go beyond the negative impact of burnout, which suggests that work can also benefit one's general well-being. Thus, it is important to consider simultaneously both negative (burnout) and positive (work engagement) states at work, and although inter-related, their effects do not completely overlap. In contrast, burnout and work engagement contribute independently and uniquely to predicting depressive symptoms and life satisfaction. Similarly, our study supports the view (e.g. McDowell, 2010) that healthrelated research should not only focus on symptoms and disease but also on dimensions reflecting health-related quality of life and truly positive well-being, e.g. work engagement and life satisfaction. Practically, workplace interventions to reduce burnout and foster work engagement may also extend their influence beyond work and build general well-being among employees.

\section{Role of funding source}

Our study project was supported by the Finnish Work Environment Fund (FWEF). The Finnish Institute of Occupational Health (FiOH) takes care of all the archiving conditions and the archiving conditions are clearly defined by FiOH and known by FWEF and therefore there are no problems or unclear issues with archiving requirements.

\section{Conflict of interest}

The authors declare we have no conflicts of interests.

\section{Acknowledgments}

This study was supported by the Finnish Work Environment Fund (project no. 110152).

\section{References}

Adams, G.A., King, L.A., King, D.W., 1996. Relationships of job and family involvement, family social support, and work-family conflict with job and life satisfaction. The Journal of Applied Psychology 81, 411-420.

Ahola, K., Hakanen, J.J., 2007. Job strain, burnout and depressive symptoms: a prospective study among dentists. Journal of Affective Disorders 104, 103-110.

Ahola, K., Honkonen, T., Virtanen, M., Koskinen, S., Kivimäki, M., Lönnqvist, J., 2008. Occupational burnout and medically certified absence: a population-based study of Finnish employees. J. Psychosom. Res. 64, 185-193.

Ahola, K., Kivimäki, M., Honkonen, T., Virtanen, M., Koskinen, S., Vahtera, J., Lönnqvist, J., 2009a. Occupational burnout and medical certified sickness absence: a population based study of Finnish employees. Journal of Psychosomatic Research 64, 185-193.

Ahola, K., Toppinen-Tanner, S., Huuhtanan, P., Koskinen, A., Väänänen, A., 2009b. Occupational burnout and chronic work disability: an eight-year cohort study on pensioning among Finnish forest industry workers. Journal of Affective Disorders 115, 150-159.

Ahola, K., Honkonen, T., Isometsä, E., Kalimo, R., Nykyri, E., Aromaa, A., Lönnqvist, J., 2005. The relationship between job-related burnout and depressive disorders-results from the Finnish health 2000 study. Journal of Affective Disorders 88, 55-62.

Ahola, K., Honkonen, T., Kivimäki, M., Virtanen, M., Isometsä, E., Aromaa, A. Lönnqvist, J., 2006. Contribution of burnout to the association between job strain and depression: the health 2000 study. Journal of Occupational and Environmental Medicine 48, 1023-1030.

Airila, A., Hakanen, J.J., Punakallio, A., Lusa, S., Luukkonen, R., 2012. Is work engagement related to work ability beyond working conditions and lifestyle factors? International Archives of Occupational and Environmental Health. doi:10.1007/s00420-012-0732-1.

Allen, T.D., Herts, D.E.L., Bruck, C.S., Sutton, M., 2000. Consequences associated with work-to-family conflict: a review and agenda for future research. Journal of Occupational Health Psychology 5, 278-308.

Anderson, S.E., Williams, L.J. 1992. Assumptions about unmeasured variables with studies of reciprocal relationships: the case of employee attitudes. The Journal of Applied Psychology 77, 638-650.

Doty, D., Glick, W., 1998. Common methods bias: does common methods variance really bias results? Organizational Research Methods 1, 374-406.

Bakker, A.B., Schaufeli, W.B., Demerouti, E., Janssen, P.M.P., Van der Hulst, R., Brouwer, J., 2000. Using equity theory to examine the difference between burnout and depression. Anxiety, Stress, and Coping 13, 247-268.

Beck, A.T., Beck, R.W., 1972. Screening depressed patients in family practice. A rapid technic. Postgraduate Medicine 52, 81-85. 
Browne, M.W., Cudeck, R., 1993. Alternative ways of assessing model fit. In: Long, J.S. (Ed.), Testing Structural Equation Models. Sage, Newbury Park, pp. 136-162.

Byrne, B., 2001. Structural Equation Modeling with AMOS, Basisc Concepts, Applications, and Programming. Lawrence Erlbaum Associates, Hillsdale, New Jersey.

Byrne, B., Baron, P., Balev, J., 1996. The Beck Depression Inventory: testing for its factorial validity and invariance across gender for Bulgarian nonclinical adolescents. Personality and Individual Differences 21, 641-651.

Chida, Y., Steptoe, A., 2008. Positive psychological well-being and mortality: a quantitative review of prospective observational studies. Psychosomatic Medicine 70, 741-756.

Cordes, C.L., Dougherty, T.W., 1993. A review and integration of research on job burnout. Academy of Management Review 18, 621-656.

Erdogan, B., Bauer, T.N., Truxillo, D.M., Masfield, L.R., 2011. Whistle while you work: a review of the life satisfaction literature. Journal of Management. doi:10.1177/0149206311429379.

Faragher, E.B., Cass, M., Cooper, C.I., 2005. The relationship between job satisfaction and health: a meta-analysis. Occupational and Environmental Medicine 62, 105-112.

Freudenberger, H.J., 1974. Staff burn-out. Journal of Social Issues 30, 159-165.

Freudenberger, H.J., Richelson, G., 1980. Burnout: The High Cost of High Achievement. Garden City, New York, NY.

Glass, D.C., McKnight, J.D., 1996. Perceived control, depressive symptomatology, and professional burnout: a review of the evidence. Psychology \& Health 11, 23-48.

Gollob, H., Reichardt, C., 1991. Interpreting and estimating indirect effects assuming time lags really matter. In: Collins, L., Horn, J. (Eds.), Best Methods for the Analysis of Change: Recent Advances, Unanswered Questions, Future Directions. American Psychological Association, Washington, pp. 243-259.

Hakanen, J.J., 2004. Hammaslääkäreiden työhyvinvointi Suomessa (Workrelated well-being among Finnish dentists). Finnish Institute of Occupational Health, Helsinki.

Hakanen, J.J., Schaufeli, W.B., Ahola, K., 2008a. The job demands-resources model: a three-year cross-lagged study of burnout, depression, commitment, and work engagement. Work and Stress 22, 224-241.

Hakanen, J.J., Perhoniemi, R., Toppinen-Tanner, S., 2008b. Positive gain spirals at work: from job resources to work engagement, personal initiative and work-unit innovativeness. Journal of Vocational Behavior 73, 78-91.

Hakanen, J.J., Bakker, A.B., Jokisaari, M., 2011a. A 35-year follow-up study on burnout among Finnish employees. Journal of Occupational Health Psychology 16, 345-360.

Hakanen, J.J., Peeters, M., Perhoniemi, R., 2011b. Enrichment processes and gain spirals at work and at home: a three-year cross-lagged panel study. Journal of Occupational and Organizational Psychology 84, 8-30.

Halbesleben, J.R.B., 2010. A meta-analysis of work engagement: relationships with burnout, demands, resources, and consequences. In: Bakker, A.B., Leiter, M.P. (Eds.), Work Engagement: A Handbook of Essential Theory and Research. Psychology Press, New York, NY, pp. 102-117.

Hobfoll, S.E., Shirom, A., 2000. Conservation of resources theory: applications to stress and burnout management in the workplace, In: Golembiewski, R.T. (Ed.), Handbook of Organizational Behavior, 2nd Revised Edition. Marcel Dekker, NY, pp. 57-81.

Hobfoll, S.E., 1998. Stress, Culture, and Community: The Psychology and Philosophy of Stress. Plenum Press, NY

Hobfoll, S.E., 2001. The influence of culture, community, and the nested-self in the stress process: advancing conservation of resources theory. Applied Psychology-an International Review 50, 337-370.

Hoyle, R.H., Panter, A.T., 1995. Writing about structural equation models. In: Hoyle, R.H. (Ed.), Structural Equation Modeling: Concepts, Issues, and Applications. Sage, Thousand Oaks, pp. 158-176.

Hu, L., Bentler, P.M., 1999. Cutoff criteria for fit indices in covariance structure analysis: conventional criteria versus new alternatives. Structural Equation Modeling 6, 1-55.

Iacovides, A., Fountoulakis, K.N., Moysidou, Ch., Ierodiakonou, Ch., 1999. Burnout in nursing staff: is there a relationship between depression and burnout? International Journal of Psychiatry in Medicine 29, 421-433.

Iacovides, A., Fountoulakis, K.N., Kaprinis, St, Kaprinis, G., 2003. The relationship between job stress, burnout, and clinical depression. Journal of Affective Disorders 75, 209-221.

Innstrand, S.T., Langballe, E.M., Falkun, E., 2012. A longitudinal study of the relationship between work engagement and symptoms of anxiety and depression. Stress and Health 28, 1-10.

Lee, R.T., Ashforth, B.E., 1996. A meta-analytic examination of the correlates of the three dimensions of job burnout. The Journal of Applied Psychology $81,123-133$.

Leiter, M., 1992. Burnout as a crisis in self-efficacy: conceptual and practical implications. Work and Stress 6, 107-115.
Leiter, M.P., Durup, J., 1994. The discriminant validity of burnout and depression: a confirmatory factor analytic study. Anxiety, stress, and coping 7, 357-373.

Maslach, C., 1976. Burned-out. Human Behavior 9, 16-22.

Maslach, C., 1993. Burnout: a multidimensional perspective. In: Schaufeli, W.B., Maslach, C., Marek, T. (Eds.), Professional Burnout: Recent Developments in Theory and Research. Taylor \& Francis, Washington, DC, pp. 19-32.

Maslach, C., Jackson, S.E., 1981. The measurement of experienced burnout. Journal of Occupational Behaviour 2, 99-113.

Maslach, C., Schaufeli, W., Leiter, M.P., 2001. Job burnout. Annual Review of Psychology 52, 397-422.

Maslach, C., Leiter, M.P., 1997. The Truth About Burnout: How Organizations Cause Personal Stress and What to do About it. Jossey-Bass, San Francisco.

McDowell, I., 2010. Measures of self-perceived well-being. Journal of Psychosomatic Research 69, 69-79.

McKnight, J.D., Glass, D.C., 1995. Perceptions of control, burnout, and depressive symptomatology: a replication and extension. Journal of Consulting and Clinical Psychology 63, 490-494.

Nyklíček, I., Pop, V.J., 2005. Past and familial depression predict current symptoms of professional burnout. Journal of Affective Disorders 88 , 63-68.

Pavot, W., Diener, E., 1993. Review of the satisfaction with life scale. Psychological Assessment 5, 164-172.

Pavot, W., Diener, E., 2008. The Satisfaction With Life Scale and the emerging construct of life satisfaction. The Journal of Positive Psychology 3, 137-152.

Ployhart, R.E., Vandenberg, R.J., 2010. Longitudinal research: the theory, design, and analysis of change. Journal of Management 36, 94-120.

Roelofs, J., Verbraak, M., Keijsers, G.P.J., De Bruin, M.B.N., Schmidt, A.J.M., 2005. Psychometric properties of a Dutch version of the Maslach Burnout Inventory-General Survey (MBI-DV) in individuals with and without clinical burnout. Stress and Health 21, 17-25.

Ryan, M.R., Deci, E.L., 2001. On happiness and human potentials: a review of research on hedonic and eudaimonic well-being. Annual Review of Psychology 52, 141-166.

Salanova, M., Llorens, S., Schaufeli, W.B., 2011. "Yes, I Can, I Feel Good, and I Just Do It!" on gain cycles and spirals of efficacy beliefs, affect, and engagement. Applied Psychology-an International Review 60, 255-285.

Salanova, M., Schaufeli, W.B., 2008. A cross-national study of work engagement as a mediator between job resources and proactive behavior. International Human Resource Management 19, 116-131.

Salanova, M., Schaufeli, W.B., Xanthopoulou, D., Bakker, A.B., 2010. Gain spirals of resources and work engagement. In: Bakker, A.B., Leiter, M.P. (Eds.), Work Engagement: A Handbook of Essential Theory and Research. Psychology Press, NY, pp. 118-131.

Schaufeli, W.B., Bakker, A.B., 2010. The conceptualization and measurement of work engagement. In: Bakker, A.B., Leiter, M.P. (Eds.), Work Engagement: A Handbook of Essential Theory and Research. Psychology Press, New York, NY, pp. 10-24.

Schaufeli, W.B., Bakker, A., Schaap, C., Kladler, A., Hoogduin, C.A.L., 2001. On the clinical validity of the Maslach Burnout Inventory and the Burnout Measure. Psychology \& Health 16, 565-582.

Schaufeli, W.B., Bakker, A.B., Van Rhenen, W., 2009. How changes in job demands and resources predict burnout, work engagement, and sickness absenteeism. Journal of Organizational Behavior 30, 893-917.

Schaufeli, W.B., Enzmann, D., 1998. The Burnout Companion to Study \& Practice: A Critical Analysis. Taylor \& Francis, London.

Schaufeli, W.B., Salanova, M., 2006. Work engagement. An emerging psychological concept and its implications for organizations. In: Gilliland, S.W., Steiner, D.D., Skarlicki, D.P. (Eds.), Research in Social Issues in Management (Volume 5): Managing Social and Ethical Issues in Organizations. Information Age Publishers, Greenwich, pp. 135-177.

Schaufeli, W.B., Salanova, M., 2007. Efficacy or inefficacy, that's the question: burnout and work engagement, and their relationships with efficacy beliefs. Anxiety, Stress, and Coping 20, 177-196.

Schaufeli, W.B., Salanova, M., González-Roma, V., Bakker, A.B., 2002. The measurement of engagement and burnout: a two sample confirmatory factor analytic approach. Journal of Happiness Studies 3, 71-92.

Schaufeli, W.B., Taris, T.W., 2005. The conceptualization and measurement of burnout: common ground and worlds apart. Work and Stress 19, 256-262.

Schaufeli, W.B., Taris, T.W., Van Rhenen, W., 2008. Workaholism, burnout and engagement three of a kind or three different kinds of employee well-being. Applied Psychology-an International Review 57, 173-203.

Sears Jr., S.F., Urizar, G.G., Evans, G.D., 2000. Examining a stress-coping model of burnout and depression in extension agents. Journal of Occupational Health Psychology 5, 56-62. 
Seligman, M.E.P., Csikszentmihalyi, M., 2000. Positive psychology. An introduction. The American Psychologist 55, 5-14.

Seppälä, P., Mauno, S., Kinnunen, M., Feldt, T., Juuti, T., Tolvanen, A., Rusko, H., 2012. Is work engagement related to healthy cardiac autonomic activity? Evidence from a field study among Finnish women workers. J. Positive Psychol. 7, 95-106.

Shimizu, T., Feng, Q., Nagata, S., 2005. Relationship between turnover and burnout among Japanese hospital nurses. Journal of Occupational Health 47, 334-336.

Shirom, A., 2003. Job-related burnout: a review. In: Quick, J.C., Tetrick, L.E. (Eds.), Handbook of Occupational Health Psychology. American Psyhological Association, Washington, DC, pp. 245-264

Shirom, A., Ezrach, Y., 2003. On the discriminant validity of burnout, depression and anxiety: a re-examination of the burnout measure. Anxiety, Stress, and Coping 16, 83-97.

Taris, T., 2006a. Is there a relationship between burnout and objective performance? A critical review of 16 studies. Work and Stress 20, 316-334.
Taris, T., 2006b. Bricks without clay: on urban myths in occupational health psychology. Work and Stress 20, 99-104

Toppinen-Tanner, S., Ahola, K., Koskinen, A., Väänänen, A., 2009. Burnout predicts hospitalization for metal and cardiovascular disorders: 10-year prospective results from industrial sector. Stress and Health 25, 287-296.

Ylipaavalniemi, J., Kivimäki, M., Elovainio, M., Virtanen, M., KeltikangasJärvinen, L., Vahtera, J., 2005. Psychosocial work characteristics and incidence of newly diagnosed depression: a prospective cohort study of three different models. Social Science \& Medicine 61, 111-122.

Warr, P.B., 1987. Work, Unemployment, and Mental Health. Oxford University Press, Oxford.

Wheaton, B., Muthén, B., Alwin, D., Summers, G., 1977. Assessing reliability and stability in panel models. In: Heise, D.R. (Ed.), Sociological Methodology. Jossey-Bass Inc, San Francisco, pp. 84-136.

Xanthopoulou, D., Bakker, A.B., Demerouti, E., Schaufeli, W.B., 2009. Reciprocal relationships between job resources, personal resources, and work engagement. Journal of Vocational Behavior 74, 235-244. 